\title{
Das relações entre posse, localização e existência em Apurinã \\ (Aruák)
}

\author{
On the relations between possession, location and existence in Apurinã (Arawak)
}

\author{
Marília Fernanda Pereira de FREITAS* \\ Universidade Federal do Pará (UFPA) \\ Sidney da Silva FACUNDES ${ }^{* *}$ \\ Universidade Federal do Pará (UFPA)
}

\begin{abstract}
RESUMO: Em Apurinã, língua Aruák falada ao longo de vários afluentes do rio Purus, sudoeste do Amazonas, as noções de posse, localização e existência podem ser expressas por uma mesma forma verbal. Em certas variedades da língua, o sufixo locativo pode expressar também posse em construções nominais. Essa característica de Apurinã, contudo, não é um caso isolado, uma vez que, em diferentes línguas, é recorrente a codificação linguística da posse estar relacionada à de localização e existência (cf.: HEINE, 1997, 2001; BARON; HERSLUND, 2001; STASSEN, 2009, entre outros). Neste artigo, buscaremos mostrar as relações conceituais e gramaticais entre esses três conceitos em Apurinã, focalizando a forma verbal awa, por meio da qual é possível verificar sincronicamente que a posse teve como domínio fonte a existência em construções verbais, dada a ocorrência de esquemas de eventos (HEINE, 1997, 2001) que revelam processos de gramaticalização operando na língua.
\end{abstract}

PALAVRAS-CHAVE: Posse. Localização. Existência. Gramaticalização. Apurinã.

\begin{abstract}
In the Apurinã language (Arawak), spoken along several tributaries of the Purus river, southeastern Amazonas State, Brazil, notions of possession, location and existence can be expressed by the same verbal form. In certain varieties of the language, the locative suffix may also express ownership in nominal constructions. This characteristic of the Apurinã language, however, is not an isolated case, since, in different languages, the linguistic codification of possession is related to location and existence (see HEINE, 1997, 2001; BARON and HERSLUND, 2001; STASSEN, 2009, among others). In this paper, we will try to show the conceptual and grammatical relationships between these three concepts in Apurinã, focusing on the verbal form awa, by means of which it is possible to determine synchronically that the possession had as source domain its existence in verbal constructions, given the occurrence of Event Schemas (Heine, 1997 and 2001) that reveal grammaticalization processes operating in the language.
\end{abstract}

KEYWORDS: Possession. Location. Existence. Grammaticalization. Apurinã.

*Doutora em Estudos Linguísticos pela Universidade Federal do Pará. Professora do Instituto de Letras e Comunicação, Faculdade de Letras, na mesma instituição.E-mail: mfpf31@yahoo.com.br

${ }^{* *}$ Doutor em Linguística pela University of New York at Buffalo. Professor do Programa de PósGraduação em Letras da Universidade Federal do Pará. E-mail: sfacundes@gmail.com 


\section{Considerações iniciais}

$\mathrm{Na}$ literatura linguística de base tipológico-funcional, recorrentemente evidencia-se a estreita relação que a noção de posse pode estabelecer com outras noções, em diferentes línguas. De modo geral, a posse pode ser compreendida como uma 'relação' envolvendo, necessariamente, um possuidor a quem pertenceria um dado item possuído. Entretanto, quando perguntado tanto a um leigo quanto a um linguista, ambos concordam em dizer que sentenças como (i) João tem uma moto constitui um caso 'real' de posse, enquanto sentenças formalmente idênticas como: (ii) Frank tem uma irmã; (iii) Uma aranha tem oito pernas; (iv) Mandy tem uma cesta no colo; (v) Bill tem gripe não são vistas como posse em um sentido prototípico (STASSEN, 2009, pp.10-11), expressam, de (ii) a (v), outros tipos de noções mais específicas, tais como parentesco, relações parte/todo, disponibilidade de algo para alguém, estado, por exemplo.

Essas diferentes noções que o mesmo verbo "ter", no caso do português, pode expressar são derivadas de diferentes subtipos semânticos de posse, que variam de autor para autor, mas que, em linhas gerais, podem ser sintetizados em quatro subtipos, com base nos parâmetros contato permanente (proximidade espacial e estabilidade temporal) e controle (cf.: STASSEN, 2009):

a) posse alienável: a relação entre possuidor e possuído não é indissolúvel ou inerente, é o caso canônico de posse. Embora essa relação de posse seja vista como relativamente estável temporalmente, esta, prototipicamente, continua a existir apenas enquanto o possuidor escolhe mantê-la, tendo, portanto, controle sobre a relação (exemplo (i), acima);

b) posse inalienável: ocorre em relações de posse envolvendo partes do corpo e termos de parentesco, relações parte/todo, entre outras noções, não envolve controle do possuidor sobre o possuído. É evidente a proximidade espacial e a estabilidade temporal dos inalienáveis prototípicos, já que, em circunstâncias normais, uma pessoa não pode se separar de uma parte de seu corpo ou deixar de ser um membro da sua família enquanto existir (exemplos (ii) e (iii), acima);

c) posse abstrata: ocorre quando o item possuído não é um objeto físico, o que pode ser visto no exemplo: “Não tenha medo!”. A noção de controle entre 
possuidor e possuído está claramente ausente. Eventos desse tipo podem ser caracterizados, pelo menos prototipicamente, como não permanentes, referindose a estados físicos ou mentais de natureza transitória (exemplo (v), acima);

d) posse temporária: corresponde à disponibilidade de algo para alguém, em algum ponto na escala temporal, não sendo relevante se o possuidor é de fato dono ou não do objeto temporariamente possuído. O contato entre possuidor e possuído é normalmente visto como acidental, não permanente; mas, enquanto o possuidor estiver estabelecendo a relação de posse com o possuído, o primeiro exerce controle sobre o segundo (exemplo (iv), acima).

Talvez, esses diferentes subtipos decorram do fato de que a posse é uma noção relativamente abstrata, difícil de definir explicitamente, mas fundamentada em intuições bastante consistentes, conforme propõe Stassen (2009). Há de se considerar, entretanto, que, para algumas dessas noções diferentes ligadas à codificação formal da posse, temos evidências bastante consistentes, dentro dos estudos tipológicos, que permitem explicar essa aproximação da posse com outros domínios de modo mais acurado. Vejamos os exemplos ${ }^{1}$ da língua Apurinã em (1), retirados de Freitas (2017):

$$
\begin{array}{cll}
\text { a. Pitha } & \text { awa-ry }^{2} & \text { xamynaky? } \\
2 \text { SG } & \text { haver-3SG.M.O } & \text { espingarda }
\end{array}
$$

'Você tem espingarda?'

\footnotetext{
${ }^{1}$ Nas glosas, $\mathrm{SG}=$ singular; $\mathrm{PL}=$ plural; 1 = primeira pessoa $; 2=$ segunda pessoa; 3 = terceira pessoa; $\mathrm{M}=$ masculino; $\mathrm{F}=$ feminino; $\mathrm{S}=$ sujeito; $\mathrm{O}=$ objeto; $\mathrm{ASSOC}=$ associativo; FRUSTR = frustrativo; $\mathrm{LOC}=$ locativo; DAT = dativo; POSSD = possuído; N.POSSD = não possuído; $\mathrm{FOC}=$ foco; $\mathrm{NC}=$ nome classificatório; ENF = enfático; PRED = predicado; DISTR = distributivo; IPFTV = aspecto imperfectivo; $\mathrm{FUT}=$ futuro; REL $=$ relativizador; N.PROP $=$ nome próprio.
}

${ }^{2}$ Em Apurinã, há um conjunto de marcas pronominais presas aos verbos como enclíticos que codificam ou são correferenciaisao objeto de verbos transitivos, mas também podem codificar ou ser correferenciais ao argumento único de um verbo descritivo objetivo, conforme definido por Facundes (2000). A seguir, o quadro com essas formas pronominais presas:

\begin{tabular}{|c|c|c|}
\cline { 2 - 3 } \multicolumn{1}{c|}{} & Singular & Plural \\
\hline 1 & - nu & -wa \\
\hline 2 & $-\mathrm{i}$ & $-\mathrm{i}$ \\
\hline $3 \mathrm{M}$ & - ry & -ry \\
\hline $3 \mathrm{~F}$ & $-\mathrm{ru}$ & - ru \\
\hline
\end{tabular}

Fonte: Facundes (2000, tradução nossa). 
b.Ywa, ĩtãnuru-kata, imiakure-kata awa-ma awinhi mitha-ry-ã

3SG.M esposa.de-ASSOC filhos.de-ASSOC haver-FRUSTR casa grande-3SG.M.O-LOC

'Ele, a esposa e os filhos moravam (estavam, viviam) em uma casa grande.'

c. Awa-ry A $^{3}$ ithu nhipukury i ỹarỹã

haver-3SG.M.O muito comida e bebida

'Tem muita comida e bebida.'

d. Atha-munhi awa ximaky

1PL-DAT haver peixe

'Nós temospeixe.' ou 'Tem peixe pra nós.'

Em (1), temos a expressão tanto de posse estrita/alienável, exemplo (1a), quanto de localização, em (1b), e de existência (1c). Em (1d), temos a posse sendo expressa em uma construção existencial, em que, literalmente, se afirma a existência de algo para alguém. Em todos os exemplos em (1) temos uma mesma forma verbal, awa, que pode expressar posse, localização e existência, em construções sintáticas específicas. Levando em conta esse fato da língua Apurinã, focalizaremos, neste trabalho, especificamente os casos em que a codificação formal da posse se relaciona com a expressão de localização e, sobretudo, de existência. Os dados em que essa pesquisa se baseia foram coletados, inicialmente, em extensivas visitas ao campo, realizadas por um dos autores, em dezenas de diferentes comunidades Apurinã, ao longo de quase 30 anos; e em 5 visitas ao campo, entre os anos de 2014 e 2017, neste último caso, em pesquisa direcionada especificamente para o fenômeno da posse. Os métodos de coleta incluíram textos e entrevistas utilizando questionários ou listas de palavras.

${ }^{3}$ Outros morfemas diferentes, também codificados sob a forma -ry, ocorrem na língua Apurinã, como em nhipuku-ry (comida-POSSD) 'comida', em que -ry marca uma subclasse de nomes alienáveis que são marcados tanto na forma não possuída (por -ry), quanto na forma possuída (por -re). Outro morfema codificado por -ry corresponde à marca de gênero masculino em nomes (cf.: FACUNDES, 2000). 


\section{Posse e localização}

Alguns autores compreendem a posse não como um conceito independente, considerando uma Hipótese Localista ${ }^{4}$ (isto é, considerando a noção de posse como um subdomínio do conceito de localização, como se a posse fosse um subtipo de relação locativa), segundo a qual "[...] a posse seria uma forma de relação locativa (talvez um pouco específica, ou resultado de extensão metafórica)" (STASSEN, 2009, p.12 tradução nossa); a posse, portanto, segundo esse tipo de abordagem, seria uma forma especial de relação locativa. Um forte argumento em favor dessa hipótese refere-se ao fato de, em muitas línguas não relacionadas, a expressão de posse ser claramente paralela (ou, em alguns casos, até mesmo idêntica) à expressão de relações locativas, como ilustram os exemplos em (1), da língua Apurinã, e também os vistos em (2), da língua Sango, a seguir:

(2) Língua Sango

a. Mbi $\varepsilon k \varepsilon$ na l'hôpital

1SG estar LOC hospital

'Eu estou no hospital.'

b. Lo eke na bongo'

ele estar LOC roupa

'Ele tem uma roupa.' (Lit.: 'Ele está com uma roupa')

(SAMARIN, 1966, pp. 95 e 179 apud STASSEN, 2009, p.13, tradução nossa)

Em (2a), a forma $\varepsilon k \varepsilon$ 'estar' ocorre com sentido locativo, enquanto que a mesma forma, em (2b), ocorre com sentido possessivo, ilustrando, portanto, a aproximação conceitual entre localização e posse.

Em algumas variedades da língua Apurinã, há casos em que o locativo é usado em construções possessivas, conforme dados de Freitas (2017):

${ }^{4}$ Location Hypothesis (STASSEN, 2009, p.12). 
(3)

$\begin{array}{lll}\text { a. Awa } & \text { kãkity } & \text { keku-txĩ-ã } \\ \text { haver } & \text { gente } & \text { rede.de-N.POSSD-LOC }\end{array}$

'Tem uma pessoa na rede.'

b. Nuta-ã-ra wera kaisuru

1SG-LOC-FOC essa pedra

'Essa pedra aí é minha.' (Lit.: 'Em mim, essa pedra.')

No exemplo (3a), acima, observa-se o emprego da marca de locativo - $\tilde{a}$ atrelada ao nome não possuído $k e k u$-txi 'rede', que designa o ponto espacial em que o termo kãkity 'gente' está localizado; em (3b), por outro lado, a mesma marca -ã se liga ao pronome nuta, nesse caso, indicando não mais localização espacial estrita, e sim posse, pertencimento.

Em (4), mais alguns exemplos retirados de Freitas (2017):

(4)

a. Nuta-ã aã-myna-tsuta

1SG-LOC NC.planta.de-NC.comprido.de-NC.tronco.de

'Meu tronco de árvore.' (Lit.: 'O tronco de árvore em mim.')

b. Uwa-ã aã-kutsa

3SG.F-LOC NC.planta.de-NC.raiz.de

'A raiz dela (da árvore).' (Lit.: 'A raiz nela.')

c. Nuta-ã aã-myna-pury

1SG-LOC NC.planta.de-NC.comprido.de-NC.galho.de

'Meu galho de árvore.' (Lit.: 'O galho de árvore em mim.')

d. Nuta-ã apyryta

1SG-LOC cesta

'Minha cesta.' (Lit.: 'A cesta em mim.') 
e. Nuta-ã putxuary

1SG-LOC açúcar

'Meu açúcar.' (Lit.: 'O açúcar em mim.')

f. Nuta-ã-ra kitxiti

1SG-LOC-FOC patauá (fruta como o açaí, da qual se extrai o sumo para alimentação)

'O patauá é meu.' (Lit.: 'O patauá em mim.’)

g. Nuta-ã parithu

1SG-LOC fósforo

'Meu fósforo.' (Lit.: 'O fósforo em mim.')

h. Nuta-ã-ra sytu

1SG-LOC-FOC mulher

'A mulher é minha.' (Lit.: 'A mulher em mim.')

As ocorrências em (4), em que o locativo ocorre expressando posse, são mais recorrentemente interpretadas (nas variedades da língua em que tais construções são usadas) como construções a serem utilizadas em contextos pragmaticamente mais enfáticos (construções dêiticas como Nuta-ãiie 'Isso é meu' Lit.: 'Isso em mim' reforçam essa interpretação), em comparação com outros padrões de marcação de posse.

Por outro lado, afirma Stassen (2009), é possível admitir que esse paralelismo entre a codificação do locativo e da posse certamente não é universal. O autor assume a posição de que "[...] a localização não pode ser vista como um modelo suficiente para a noção cognitiva/semântica da posse. [...] para explicar a noção pré-teórica de 'pertencimento', a uniformidade da localização é um ingrediente necessário, mas não é o único" (STASSEN, 2009, p. 14, tradução nossa). Tal como esse autor e alguns outros (BARON; HERSLUND, 2001; HEINE, 1997), admitimos aqui o posicionamento segundo o qual a localização constitui parte necessária à compreensão do conceito de posse, mas esta não corresponde à única dimensão a ser considerada para que se compreenda tal conceito. A exemplo disso, no caso da língua Apurinã, não teríamos evidências suficientes para definir a posse enquanto subdomínio da localização, uma 
vez que, nos casos de posse nominal, as construções em que ocorre o locativo $-\tilde{a}$ indicando posse são raras e restritas a certos dialetos da língua, sendo que a maioria das construções de posse nominal na língua não inclui o uso dessa marca de locativo. Em se tratando de construções de posse verbal, não temos evidências sincrônicas da localização como domínio fonte para a posse. Por outro lado, temos evidências substanciais para identificar como domínio fonte da posse a existência (o que será tratado mais adiante).

\section{Existência como domínio fonte para a posse em Apurinã}

Segundo Baron e Herslund (2001), muitas línguas apresentam semelhanças estruturais marcantes não só entre construções locativas e possessivas, mas também entre possessivas e existenciais. Construções existenciais são frequentemente encontradas como um tipo de construção possessiva. A natureza intrinsecamente existencial da posse, de acordo com Baron e Herslund (2001), tem seu ponto de partida na afirmação de Benveniste (1966 apud BARON; HERSLUND, 2001) de que 'avoir' ('ter') é um 'être' ('ser/estar') invertido (seria aproximadamente como o par de sentenças em português a seguir: Ele tem dinheiro x $O$ dinheiro $\underline{e}$ dele).

Como dito anteriormente, a forma verbal awa (atestada por FACUNDES, 2000, cuja descrição foi posteriormente aprofundada por FREITAS, 2017), da língua Apurinã, pode significar 'ter', 'viver/estar em/com' ou 'existir', funcionando, respectivamente, como verbo pleno ter, locativo ou existencial, ilustrando de modo bastante claro o relacionamento entre as noções de posse, localização e existência. A seguir, vemos exemplos ${ }^{5}$ em que $a w a$ admite uma interpretação possessiva:
(5) a. $[\text { Pitha }]^{\mathrm{A}}$ awa-ry $\quad[\text { nhipuku-ry }]^{\mathrm{O}}$ ?
2SG haver-3SG.M.Ocomida-N.POSSD
'Você tem comida?'

\footnotetext{
${ }^{5}$ Exemplos de Freitas (2017). "A" corresponde ao argumento mais agentivo de uma construção transitiva; "O" se refere ao argumento menos agentivo de uma construção transitiva (ou ao argumento único de um verbo intransitivo descritivo objetivo, cf.: FACUNDES, 2000); "S" denota o argumento único de uma construção intransitiva.
} 
b. $[\text { Nuta }]^{\mathrm{A}}$ awa-pyty-ka $\quad[\text { awiri yky }]^{\mathrm{O}}$.

1SG haver-ENF-PRED rapé semente.

'Eu tenho mesmo semente de rapé.'

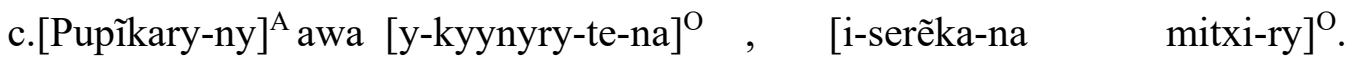
índio-PL haver 3PL.M-xingané6-POSSD-3PL.M 3PL.M-dança.de-3PL.M ser.primeiro-3SG.M.O

'Os Apurinã têm a festa deles, as primeiras danças deles (as danças tradicionais).'

d. $[\mathrm{Uwa}]^{\mathrm{A}}$ awa $\quad[\text { kaiãũ-puku amary-ny-ky }]^{\mathrm{O}}$

3SG.F haver muito-DISTR criança-PL-NC.pequeno

'Ela tinha muitos filhos.'

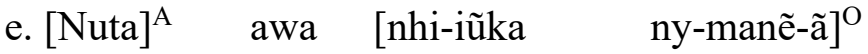

1SG haver 1SG-pintura.de 1SG-corpo.de-LOC

'Eu tenho pintura no corpo.' (Lit.: 'Eu tenho minha pintura no meu corpo.')

Em todos os exemplos em (5), temos as funções sintáticas de sujeito e objeto, correspondendo aos papéis semânticos de possuidor e item possuído. Assim, nas ocorrências supramencionadas, awa funciona como um verbo de dois lugares, requerendo um sujeito/possuidor e um objeto/item possuído.

Ocorre que os casos mostrados em (5) correspondem apenas àqueles exemplos mais prototípicos que envolvem o uso de awaem construções possessivas. Vejamos alguns outros exemplos ${ }^{7}$ :

$\begin{array}{cll}\text { a. Ary. }[\text { Nuta-munhi] }]^{\text {Ad.Dat }} & \text { awa-pyty-ka } & \text { [paikuma }]^{\mathrm{S}} . \\ \operatorname{sim} \text { 1SG-DAT } & \text { haver-ENF-PRED } & \text { tingui }\end{array}$

'Sim. Eu tenho tingui (tipo de cipó venenoso).' (Lit.: 'Sim. Tem (existe) mesmo tingui pra mim.')

${ }^{6}$ Festa tradicional dos Apurinã.

${ }^{7}$ Os rótulos Ad.Dat (adjunto dativo, codificando morfossintaticamente um referente não obrigatório de uma construção com verbo existencial e que, semanticamente, corresponde ao recipiente, beneficiário) e Mod.Gen (modificador genitivo, codificado por um elemento que modifica um sintagma nominal, agregando a este o sentido de item possuído, em uma construção com verbo existencial) estão sendo usados aqui conforme Heine (2001, p. 317). 
b. $[\text { Ywa-munhi }]^{\text {Ad.Dat }}$ awa $[\text { keku-txi }]^{\mathrm{S}}$

3SG-DAT haver rede.de-N.POSSD

'Ele tem rede.'(Lit.: 'Existe rede pra ele.')

c. $\left[\mathrm{N}^{\text {Mod.Gen }}-\mathrm{yry}\right]^{\mathrm{S}} \quad$ awa-panhi-ka

1SG-pai.de haver-IPFTV-PRED

'Eu ainda tenho pai.' (Lit.: 'Meu pai ainda existe.')

d. [Ywa, ĩtãnuru-kata, imiakure-kata] ${ }^{\mathrm{S}}$ awa-ma $\quad$ [awi nhimitha-ry-ã] ${ }^{\mathrm{Loc}}$

3SG.M esposa.de-ASSOC filhos.de-ASSOC haver-FRUSTR casa grande-3SG.M.O-LOC

'Ele, a esposa e os filhos moravam em uma casa grande.'

e. $[\text { Nuta ãkiri }]^{\mathrm{S}} \quad$ awa-ry $\quad[\text { paraka-ã }]^{\mathrm{Loc}}$

1SG filho.de haver-3SG.M barraca-LOC

'Minha filha está em casa'

f. $[\text { Aiku-ã }]^{\text {Loc }}$ awa-karu [Ĩkiiapa $]^{\mathrm{S}}$, pymãa-ry

casa-LOC haver-REL.S.F N.PROP perguntar-3SG.M.O

'A Îkiiapa, que tava em casa, perguntou: [...].'

Os exemplos em (6a-c), embora possam ser interpretados como casos de posse, apresentam estrutura funcional diferente daquela vista nas ocorrências mais prototípicas de posse envolvendo awa (exemplos em 5). Em (6a-b) temos, respectivamente, os sujeitos paikuma 'tingui' e kekutxi 'rede', além dos adjuntos dativos nutamunhi 'para mim' e ywamunhi 'para ele'. Facundes (2000) descreveu a posposição -munhi como uma marca de oblíquo, que se liga a nomes e pronomes, para indicar meta, benefactivo ou dativo. ${ }^{8}$ Semanticamente, sentenças como (6a-b) podem denotar uma relação de posse, envolvendo os papéis semânticos de possuidor e item possuído; mas também é possível uma interpretação existencial, em que se afirma a existência de algo, um

${ }^{8}$ É importante deixar claro que -munhi não ocorre apenas com referentes humanos, mas também com nãohumanos, como em İ-kanapyryã-ka-saakyaapuku-munhi (3SG.M-voltar-PRED-TEMP comunidade.de-DAT) 'Quando ele voltou para a comunidade [...]'. 
ente ${ }^{9} /$ item possuído, para um dado recipiente, beneficiário/possuidor. Quanto a (6c), temos o sujeito $n$-yry 'meu pai', cujo papel semântico corresponde ao de ente, que apresenta um modificador genitivo (conforme HEINE, 2001), $n y$ - ' $1^{\mathrm{a}}$ pessoa singular sujeito (em verbos) / possuidor (em nomes)', fazendo referência ao sujeito lógico da sentença, no caso da interpretação possessiva 'Eu ainda tenho pai'. Literalmente, entretanto, temos uma construção que denota a existência de um ente possuído ('Meu pai ainda existe').

Nos exemplos (6d-f), temos casos de awa com sentido locativo, significando "viver em, morar em", "estar em", em que se observa a presença dos locativos

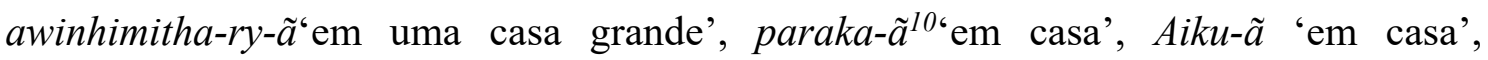
respectivamente. Há mais casos de awafuncionando como locativo, mas, neste artigo, focalizaremos o sentido possessivo e o existencial de $a w a$, defendendo a hipótese de que o sentido existencial teria sido domínio fonte para o sentido possessivo dessa forma verbal, o que será discutido mais adiante.

Assim, levando em conta os diferentes significados associados a $a w a$, e também considerando as construções existenciais em que awadenota posse, defenderemos a ideia de que os diferentes significados daforma verbal awa se relacionam como resultado de um processo de gramaticalização.

O termo "gramaticalização", segundo Heine e Reh (1984 apud TRAUGOTT; HEINE, 1991, p. 2, tradução nossa) corresponde a “[...] uma evolução por meio da qual unidades linguísticas perdem em complexidade semântica, significação pragmática, liberdade sintática e substância fonética [...]". Acreditamos ser bastante ampla e aplicável à língua Apurinã a definição proposta por Traugott e Heine (1991, p.1, tradução nossa), segundo os quais:

A gramaticalização é o processo linguístico, ao mesmo tempo diacrônico e sincrônico, de organização de categorias e de codificação [gramatical de significados e funções linguísticas]. O estudo da gramaticalização, portanto, se volta para a tensão entre a flexibilidade relativa de expressões lexicais e a codificação morfossintática mais rígida, apontando para a indeterminação relativa da língua e não para a ideia de categorias básicas discretas.

9 Optamos por adotar aqui o rótulo "ente", por o considerarmos mais apropriado para expressar o papel semântico de "algo/alguém que existe".

${ }^{10}$ Os nomes paraka (empréstimo do português, 'barraca') e aiku, ambos significando casa, moradia, são resultado de variedades dialeteia diferentes de Apurinã. 
Assim, em linhas gerais, a gramaticalização é um processo de mudança que opera nas línguas, fazendo com que uma dada estrutura linguística se torne gradativamente mais gramatical. Nesse sentido, por exemplo, um dado item linguístico que se inscreve dentro de um domínio semântico específico pode ter sua origem, sua fonte, em um outro domínio semântico; nesse caso, o domínio fonte (isto é, o domínio semântico a partir do qual um outro domínio se origina) apresenta um significado mais concreto, mais palpável, enquanto que o domínio alvo (aquele originado a partir de um domínio fonte) tende a ter um significado menos concreto, menos palpável (cf.: HEINE, 1997, 2001).

Feitas essas breves considerações acerca da definição do termo gramaticalização, passemos a uma discussão mais específica, relacionada a como a posse em Apurinã pode ser compreendida dentro dessa abordagem.

De acordo com Perniss e Zeshan (2008), entre as línguas naturais há uma sobreposição empírica substancial entre estruturas usadas para expressar existência e posse; nesse sentido, não é difícil fazer uma conexão entre "alguma coisa existindo dentro da esfera de influência de alguém" e "alguma coisa pertencendo a alguém". Assim, recorrentemente, construções de posse se originam a partir de construções existenciais ou locativas preexistentes em dada língua; ou seja, é comum o domínio da posse ter como fonte os domínios da existência e da localização.

Heine (1997) propõe a existência de certos domínios fonte, os quais chama de esquemas de evento, que correspondem a construtos de situações prototípicas, embasadas em domínios experimentais concretos (esquema de localização; esquema de acompanhamento; esquema ação; esquema fonte; esquema equativo; esquema genitivo; esquema meta; e esquema tópico). Em trabalho posterior, discutindo acerca da posse em construções verbais, Heine (2001) afirma, que (dos oito domínios fontes propostos no trabalho de 1997), construções envolvendo ter podem ser derivadas de um dos seis domínios fonte listados abaixo, em que $\mathrm{X}$ se refere ao possuidor e $\mathrm{Y}$ ao item possuído:

i. $\quad$ Esquema ação ( $\mathrm{X}$ toma, pega $\mathrm{Y}$ ): contém um verbo transitivo de aquisição ou apreensão. O verbo de ação se gramaticaliza para expressar construções de posse;

ii. Esquema localização (Y está localizado em $\mathrm{X})$ : o possuidor é conceptualizado como o lugar onde o item possuído está localizado. Por 
meio do uso de um complemento locativo, normalmente marcado no possuidor, o item possuído é expresso como estando na localização do possuidor;

iii. Esquema meta ( $\mathrm{Y}$ existe por/para $\mathrm{X}$ ): o possuidor funciona como um adjunto dativo e o item possuído é o sujeito. A posse se estabelece pela afirmação de que o item possuído existe por/para o possuidor. Este esquema está ligado à existência;

iv. Esquema genitivo (de $\mathrm{X}, \mathrm{Y}$ existe): o possuidor funciona como um modificador genitivo e o item possuído como sujeito. Também está ligado à existência;

v. Esquema acompanhamento ( $\mathrm{Y}$ está com $\mathrm{X}$ ): o item possuído é um complemento comitativo do sujeito possuidor. O possuidor é o sujeito e o item possuído o objeto.

vi. Esquema tópico (quanto a $\mathrm{X}, \mathrm{Y}$ existe): o possuidor funciona como um modificador possessivo, por aparecer na posição de tópico. Esse esquema está relacionado à existência. O relacionamento possessivo é estabelecido pela afirmação da existência do item possuído em relação ao possuidor topicalizado.

Heine (2001) acrescenta que a motivação para recorrer a expressões não possessivas para desenvolver expressões possessivas se baseia no fato de que as primeiras são mais concretas, fáceis de definir e de se referir no discurso.

Dos seis esquemas que se aplicam à posse verbal, propostos por Heine (2001), os que ocorrem na língua Apurinã são: esquema meta e esquema genitivo, ilustrados a partir dos exemplos a seguir:

(7) Esquema meta

$\begin{array}{cll}\text { a.[Nuta-munhi }]^{\text {Ad.Dat }} & \text { awa } & {[\text { ãata }]^{\text {S. }} \text {. }} \\ 1 \text { SG-DAT } & \text { haver } & \text { casco }\end{array}$

'Tem casco (tipo de canoa) pra mim.'

$\begin{array}{lll}\text { b.Awa-pyty-ka } & {\text { [awiri-ky }]^{\mathrm{S}}}^{\text {[nuta-munhi] }^{\text {Ad.Dat }}} \\ \text { haver-ENF-PRED } & \text { rapé-NC.semente,pequeno } & \text { 1SG-DAT }\end{array}$

'Eu tenho semente de rapé.' (Lit.: 'Existe mesmo semente de rapé pra mim.') 


$$
\begin{array}{clll}
\text { c. }[\text { Kyky-munhi }]^{\text {Ad.Dat }} & \text { awa-panhi-ka-ku } & {[\text { ithu }} & \text { dinhẽru }]^{\mathrm{S}} \\
\text { homem-DAT } & \text { haver-IPFTV-PRED-FUT } & \text { muito } & \text { dinheiro }
\end{array}
$$

'O homem vai ter muito dinheiro.' (Lit.: 'Ainda vai haver muito dinheiro pro homem.')

O esquema meta está ligado ao esquema da existência, uma vez que denota um item possuído que existe por/para alguém; sintaticamente, requer um sujeito (com papel semântico de item possuído/tema) e um adjunto dativo (semanticamente se referindo ao possuidor/recipiente). Assim, temos os exemplos em (7a-c), em que se observa a presença da posposição -munhi 'dativo', que se liga a um nome (exemplo 7c) ou um pronome (exemplos $7 \mathrm{a}-\mathrm{b}$ ), formando um adjunto dativo, que corresponde ao possuidor da relação de posse; o item possuído exerce função de sujeito da construção (respectivamente, ãata 'casco (canoa tradicional)', awiriky 'semente de rapé', ithu dinhẽru 'muito dinheiro').

Os próximos exemplos correspondem a ocorrências de awa derivadas do esquema genitivo:

(8) Esquema genitivo

$\begin{array}{cll}\text { a. Kuna } & \text { awa-ry } & \text { [ny }^{\text {Mod.Gen }} \text {-parĩka }^{\mathrm{S}} \\ \text { não } & \text { haver-3SG.M.O } & \text { 1SG-trabalho.de }\end{array}$

'Eu não tenho trabalho.' (Lit.: 'Não existe meu trabalho.')
b. Kaiãa-puku $\quad\left[a^{\text {Mod.Gen }} \text {-parĩka }\right]^{\mathrm{S}} \quad$ awa
muito-DISTR 1PL-trabalho.de haver

'Nós temos muito trabalho.' (Lit.: 'Existe muito nosso trabalho.')
c. $\left[\text { Py }{ }^{\text {Mod.Gen }}{ }_{-m u i a n a-r y}\right]^{\mathrm{S}} \quad$ awa-pe?
2SG-companheiro-M haver-PFTV

'(Você) tem um companheiro (pra lhe acompanhar)?' (Lit.: 'Seu companheiro já existe?')

Em (8a), temos ny-parĩka 'meu trabalho' (semanticamente designando o item possuído), modificado pela forma pronominal presa de sujeito de $1^{\mathrm{a}}$ pessoa singular (se 
referindo ao possuidor), funcionando como argumento único de $a w a$. Em (8b), o modificador genitivo $a$ - exerce o papel de possuidor e parĩka se refere ao item possuído. Em (8c) py-se refere ao possuidor emuianary ao item possuído.

Assim, a coincidência formal entre $a w a=$ com significado possessivo e $a w a=$ com significado existencial não é aleatória, uma vez que temos evidências sincrônicas de que a posse em Apurinã tem como esquema fonte a existência, uma vez que os esquemas genitivo e meta são subdomínios do primeiro: no esquema meta, algo existe para alguém; no esquema genitivo, afirma-se a existência de um ente possuído.

Em suma, por um lado, a forma verbal $a w a$, sincronicamente, pode ocorrer em construções inequivocamente existenciais, como em (9). Observe, por exemplo, que em (9a) a forma apuumary 'febre' ocorre na forma não possuída:

$\begin{array}{rlll}\text { a.Ipi ũty } & \text { atuku } \text { [apuuma-ry] }^{\mathrm{S}} & \text { kuna } & \text { awa-ika. } \\ \text { dois dia } & \text { depois febre-N.POSSD } & \text { não } & \text { haver-não.mais }\end{array}$

'Dois dias depois, não havia mais febre.'

b. Watxa puiaũ-nuka hoje pouco-apenas

'Hoje tem só pouco índio.'

$$
\begin{array}{ll}
\text { [pupỹkary] }^{\mathrm{S}} & \text { awa-ry } \\
\text { índio } & \text { haver-3SG.M.O }
\end{array}
$$

Também há ocorrências de $a w a$ inequivocamente possessivas:

$\begin{array}{clll}\text { a. } \text { [Ywa }^{\mathrm{A}} & \text { kuna } & \text { awa-ry } & \text { [y-tsupa }^{\mathrm{O},} \\ \text { 3SG.M } & \text { não } & \text { haver-3SG.M.O } & \text { 3SG.M-NC.folha }\end{array}$

\begin{tabular}{|c|c|c|}
\hline b. [Nynuwa] ${ }^{\mathrm{A}}$ awa-ry & [iumyary & apiku-munhi \\
\hline haver-3SG.M.O & macaxeira & adiante-DAT \\
\hline
\end{tabular}

'Ele não tinhadinheiro.' (Lit.: 'Ele não tinha o dinheiro dele.')

'Eles tinham macaxeira e, além disso, fruta.'

Já em certos casos em que ocorre o esquema meta, ambas as interpretações são possíveis (retomamos aqui o exemplo apresentado em 1d): 
(11)

$\begin{array}{cll}\text { a. }[\text { Atha-munhi] }]^{\text {Ad.Dat }} & \text { awa } & \text { [ximaky }^{\mathrm{S}} \\ \text { 1PL-DAT } & \text { haver } & \text { peixe }\end{array}$

'Nós temos peixe.' ou 'Tem peixe pra nós. ${ }^{11}$,

Isso nos remete aos estágios de gramaticalização, propostos por Heine (1997): no estágio I, está disponível apenas o significado fonte; no estágio II, existe ambiguidade entre o significado fonte e o alvo, ou seja, o significado pode remeter tanto à fonte quanto ao alvo; no estágio III, apenas o significado alvo está disponível. As evidências sincrônicas observadas em Apurinã apontam para uma interpretação segundo a qual a forma awa encontra-se no estágio II de gramaticalização, em que tanto o significado existencial (fonte) quanto o significado possessivo (alvo) coexistem, estão disponíveis, em certos casos, havendo ambiguidade entre as traduções portuguesas deles. Em resumo, a relação que se estabelece entre essas duas instâncias de awa (existencial e possessiva) é a de que a expressão de posse na língua se originou a partir da expressão de existência (uma vez que esta última tem um significado mais empírico, menos abstrato que a primeira), o que é bastante comum nas línguas naturais, conforme atesta a literatura sobre o assunto (cf.: HEINE, 1997 e 2001, por exemplo).

\section{Considerações finais}

Admitindo-se que tanto a existência quanto a localização são domínios fonte possíveis (e recorrentes nas línguas do mundo) para a posse e, não coincidentemente, $a w a$, como já mencionado, pode ter uma interpretação locativa (além das interpretações possessiva e existencial), haveria a possibilidade de que as ocorrências locativas de $a w a$, assim como as existenciais, pudessem ser a fonte para a posse em Apurinã.

Em construções verbais, sincronicamente, não há nenhuma construção locativa que possa ser interpretada com sentido possessivo. Em nenhuma das ocorrências da forma verbal awa com sentido locativo é possível uma interpretação possessiva, ou seja, não foi possível atestar, sincronicamente, o esquema localização (em que o possuidor é

\footnotetext{
${ }^{11}$ Diferentes colaboradores Apurinã forneceram ambas as traduções para esse exemplo.
} 
concebido como o lugar em que o item possuído está) nessa língua. Há casos, entretanto, em que o formativo - $\tilde{a}$ 'locativo' é sufixado no possuidor, em uma relação de posse nominal (por exemplo, Nuta-ãputxuary (1SG-LOC açúcar) 'meu açúcar'), mas tais usos se restringem a algumas variedades específicas da língua, ligadas a questão diatópica, e não vêm com o verbo $a w a-$.

Por outro lado, como visto na seção anterior, temos evidências robustas de que a existência tenha sido o domínio fonte da posse em Apurinã, uma vez que é possível atestar sincronicamente a presença dos esquemas meta e genitivo, conforme Heine (1997 e 2001).Nesse sentido, uma vez que $a w a$ ocorre em construções inequivocamente existenciais e também em construções inequivocamente possessivas, pode-se considerar que esta forma verbal estaria em um segundo estágio de gramaticalização, conforme Heine (1997 e 2001), uma vez que a forma fonte (existência) coexiste com seu significado alvo (posse) e, em certos casos, suas traduções para o português podem ser ambíguas.

Tipologicamente, tanto a existência como a localização constituem esquemas de eventos, isto é, construtos de situações prototípicas, embasadas em domínios experimentais concretos, conforme Heine (1997), e quando temos um caso como o de $a w a$, que pode denotar existênciaou posse, não é difícil concluir que a codificação desta última noção em Apurinã é resultado de um processo de gramaticalização, em que awaexistencial serviu de domínio fonte para a posse. Também não é possível determinar sincronicamente se awa-existencial deu origem a awa-locativoou vice-versa. Portanto, esperamos ter demonstrado que o awa-existencial deu origem ao awa-possessivo; quanto à relação destes com o awa-locativo, essa é uma questão de pesquisa que requer dados de uma investigação histórico-comparativa - o que, no entanto, seria objeto de uma outra pesquisa.

\section{REFERÊNCIAS}

BARON, Irene; HERSLUND, Michael. Dimensions of Possession. In: BARON, Irene; HERSLUND, Michael; SØRENSEN, Finn. Dimensions of Possession. Amsterdã/Filadélfia: John Benjamins Publishing Company, 2001, pp. 1-26. 
FACUNDES, Sidney da Silva. The Language of the Apurina People of Brazil (Maipure/Arawak). Nova York, Búfalo: Faculty of the Graduate School of State University of New York at Buffalo (Tese de Doutorado), 2000.

FREITAS, Marília Fernanda Pereira de. A posse em Apurinã: descrição de construções atributivas e predicativas em comparação com outras línguas Aruák. Programa de PósGraduação em Letras da Universidade Federal do Pará, Belém, (Tese de Doutorado) 2017.

HEINE, Bernd. Ways of explaining possession.In: BARON, Irene; HERSLUND, Michael; SØRENSEN, Finn (eds.). Dimensions of Possession.Amsterdã, Filadélfia: John Benjamins Publishing Company, 2001, pp. 311-328 (Typological Studies in Language, vol. 47).

- Possession: Cognitive Sources, Forces, and Grammaticalization. Cambridge: Cambridge University Press, 1997.

PERNISS, Pamela; ZESHAN, Ulrike. Possessive and Existential Constructions: introduction and overview. In: PERNISS, Pamela; ZESHAN, Ulrike (eds.). Possessive and existential constructions in sign languages. Ishara Press, Nijmegen, 2008, pp. 1-31.

STASSEN, Leon. Predicative Possession. Nova Iorque: Oxford University Press, 2009.

TRAUGOTT, Elizabeth; HEINE, Bernd (eds.). Approaches to Grammaticalization: focus on theoretical and methodological issues (vol. I). Amsterdã/Filadélfia: John Benjamins Publishing Company, 1991. 